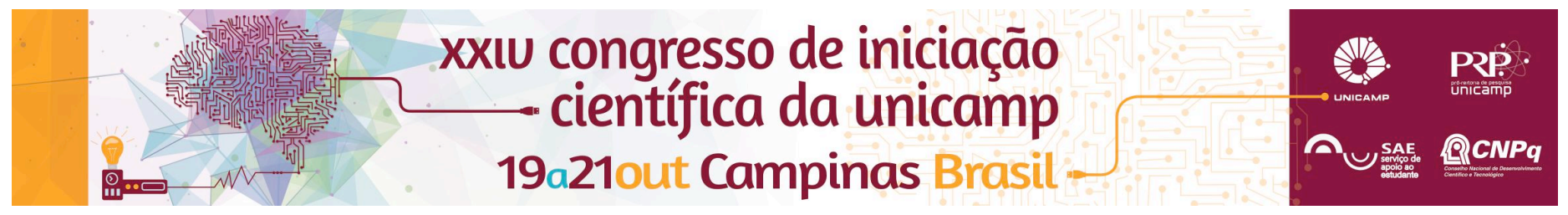

\title{
RECHARGING ELECTRIC VEHICLES IN ELECTRIC ENERGY DISTRIBUTION SYSTEMS USING LOCAL MEASUREMENTS
}

\section{Pedro B. S. Romano, Prof. Dr. Marcos J. Rider}

\begin{abstract}
The problem of charging electric vehicles is related to determine the optimal programming of recharging electric vehicles (EVs) in order to minimize the total operational costs, while satisfying operational constraints of electric energy distribution systems. To achieve this goal, it is usually needed a certain coordination level between all the EVs plugged in the network and a central controller device. Since this scientific initiation research is in its first half, first is discussed about the impact of EVs in the distribution system operation. Thereafter it'll be implemented an algorithm on OpenDSS simulator, with control actions through MatLab, for the EVs charging coordination problem using local measurements.
\end{abstract}

\section{Key words:}

charging coordination problem, electric energy distribution system, electric vehicles

\section{Introduction}

The motivation of this research is studying the impact of EVs in voltages magnitudes profiles and loads on electrical transformers of distributions systems, and purpose a distributed recharging algorithm. Two sets are being researched: (a) vehicles recharging without any control; (b) vehicles with an intelligent distributed recharging. In this part, it'll be presented the first case. The results are based and compared on the ANEEL operational limits [1].

\section{Results and Discussion}

The incorporation of EVs on electric energy distribution system causes different effects like voltage magnitude profiles rises, unbalance system, congestion on power lines and rise of power flow losses, as we can see on [2].
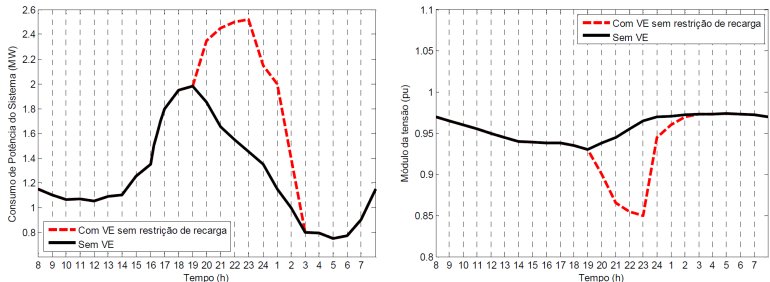

Image 1.Impact of electric vehicles on distributed systems.

The software used to generate and simulate the network is OpenDSS [3], an open source tool which offers analysis in frequency domain, as well as analysis about current distribution systems and renewable energy sources, from simple power flow calculations to daily or yearly loading simulations. Its solution algorithm is based on Newton's traditional method, despite OpenDSS represents multi-phases systems (e.g. 3-phase, neutral and ground) instead of mono-phase as in the method quoted. This simulator was chosen due to your huge capacity and coverage in this subject.

One substantial feature in this software is your COM interface with others software, as MS Excel VBA, AMPL, Python and MatLab. In this research, the intelligent EVs recharging will be manipulate through MatLab. This is an important tool that optimizes and simplify writing a program to control and customize the simulation. In MatLab code should have this header as in Image 2 that set ıns the text file circıuit solıtion and controls

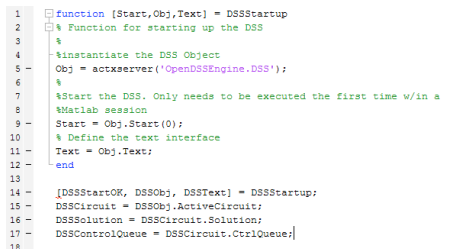

Image 2. Code that initializes OpenDSS on MatLab.

The test system used is the IEEE 123 Node Test Feeder [4] which operates at a nominal voltage of $4.16 \mathrm{kV}$ and could be tested with the additional inserted loads - in this case, the electric vehicles. The Image 3 shows the primary distribution system that was used as first simulations. Thereafter the student intends to build a secondary distribution network on all nodes, to model the EVs like loads and ranging the values of these loads to simulate the EVs charging.

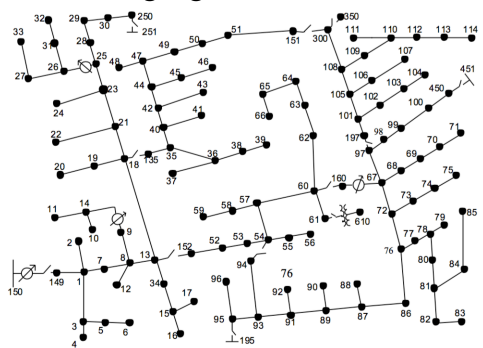

Image 3. Primary IEEE 123 Test Feeder.

\section{Conclusions}

This initiation research was initiated in April, 2016 and is in progress. According to the research advances, it should have more numerical conclusions about the impact of the EVs on the systems and aim is to develop a recharging strategy using the local measurements.

\section{Acknowledgement}

The authors would like to thank FAPESP.

\footnotetext{
ANEEL. Prodist Módulo 8: Qualidade da Energia Elétrica. Disponível em: http://www.aneel.gov.br/visualizar texto.cfm?idtxt=1877. Acesso: Dec. 2015.

${ }^{2}$ M. A. S. Masoum, P. S. Moses and S. Hajforoosh, "Distribution transformer stress in smart grid with coordinated charging of plug-in electric vehicles," 2012 IEEE PES Innovative Smart Grid Technologies, pp.1-8, 16-20 Jan. 2012.

${ }^{3}$ OpenDSS: Open Distribution System Simulator Documentation. Disponível em: http://smartgrid.epri.com/SimulationTool.aspx

IEEE Distribution Test Feeders Documentation. Disponível em: https://ewh.ieee.org/soc/pes/dsacom/testfeeders/
} 